\title{
HISTÓRIA DA EDUCAÇÃO E POLÍTICAS EDUCACIONAIS ENTRE SABERES, CONHECIMENTOS E CIRCULAÇÃO INTERNACIONAL DE DISCURSOS
}

\author{
Claudemir de Quadros (UFSM)*
}

\begin{abstract}
RESUMO
Este texto se caracteriza, sobretudo, como um exercício pelo qual se tentou perceber algumas relações entre duas áreas relevantes no âmbito da educação: história da educação e políticas educacionais. Para tanto, foram escolhidos quatro artigos publicados na revista História da Educação entre 2013 e 2015, selecionados a partir do critério de inserção internacional dos seus proponentes e porque potencializam perceber a perspectiva de circulação internacional de discursos no âmbito da formulação de políticas educacionais. Por esses textos procura-se demonstrar como aquilo que estamos acostumados a dizer é resultado de uma ampla rede de relações cuja autoria não é necessariamente nacional ou, em outros termos, que aquilo que conseguimos pensar acerca das políticas educacionais é circunscrito pelos discursos que circulam internacionalmente. Assim, o texto é atravessado por uma ideia geral: a circulação de discursos que, de um modo ou de outro, tem o potencial de estruturar, fixar, delimitar, circunscrever aquilo que pode ser considerado correto e verdadeiro. $\mathrm{O}$ esforço foi no sentido de perceber que ideias criadas, pensadas, fundamentadas pela pesquisa, pela ciência, propostas por intelectuais, lograram visibilidade e, além de contribuir para a estruturação de todo um campo de ação denominado políticas educacionais, têm o potencial de demonstrar que a formação dos sistemas escolares nacionais emergiu a partir de um amplo leque de relações internacionais.

Palavras-chave: História da educação. Políticas educacionais. Circulação de discursos. Intelectuais.
\end{abstract}

\section{ABSTRACT \\ HISTORY OF EDUCATION AND EDUCATIONAL POLICIES AMONGST KNOWLEDGES AND INTERNATIONAL DISCOURSES CIRCULATION}

This study characterizes itself mainly as an exercise in which we tried to perceive some relations between two significant areas of education: history of education and educational policies. Therefore, four articles published in the journal History of Education between 2013 and 2015 were selected based on the criterion of international insertion of its proponents. This criterion was used because such articles potentiate the perception of the perspective of international circulation of speeches in the formulation of educational policies. Based on these texts, we seek to demonstrate how what we are accustomed to say is the result of a wide network of relations whose authorship is

* Doutor em Educação pela Universidade Federal do Rio Grande do Sul (UFRGS). Licenciado em História pela Universidade de Passo Fundo (UPF). Mestre em Educação pela Universidade de Passo Fundo (UPF). Professor na Universidade Federal de Santa Maria (UFSM/RS). Atua em cursos de formação de professores e no Programa de Pós-Graduação em Educação Profissional e Tecnológica da UFSM. E-mail: claudemirdequadros@gmail.com. 
not necessarily national or, in other words, that what we can think about educational policies is restricted by speeches that have international circulation. Then, this text is circumscribed by a general idea: the circulation of speeches that, anyhow, have the potential to structure, fix, delimit, and circumscribe what can be considered correct and true. The effort of this study is to propose the perception that ideas, which were created, thought, grounded by research, by science, proposed by intellectuals, gained visibility. Besides having contributed to the structuring of a whole field of action called educational policies, these ideas have the potential to demonstrate that the formation of national school systems emerged from a wide range of international relations.

Keywords: History of education. Educational policies. Circulation of speeches. Intellectuals.

\section{RESUMEN}

\section{HISTORIA DE LA EDUCACIÓN Y POLÍTICAS EDUCACIONALES ENTRE SABERES, CONOCIMIENTOS Y CICRCULACIÓN INTERNACIONAL DE DISCURSOS}

El presente texto se caracteriza, sobre todo, como ejercicio por el que se buscó percibir algunas relaciones entre dos ares relevantes en el ámbito de la educación: historia de la educación y políticas educacionales. Para tanto, se eligió cuatro artículos publicados en la revista Historia da Educação entre 2013 e 2015, los cuales fueron seleccionados a partir de criterios de inserción internacional de sus proponentes y porque potencializan percibir la perspectiva de circulación internacional de discursos en el ámbito de la formulación de políticas educacionales. Con ello se busca demonstrar que aquello que estamos acostumbrados a decir es resultado de una amplia red de relaciones cuya autoría no es necesariamente nacional o, en otros términos, que aquello que logramos pensar a cerca de las políticas educacionales es circunscrito por los discursos que circulan internacionalmente. Así, el texto es atravesado por una idea general: la circulación de discursos que, de un modo u otro, tiene el potencial de estructurar, fijar, delimitar, circunscribir aquello que puede ser considerado correcto y verdadero. El esfuerzo fue en el sentido de percibir que ideas creadas, pensadas, fundamentadas en la investigación, por la ciencia, propuestas por intelectuales, lograron visibilidad y, más allá de contribuir para la estructuración de todo un campo de acción denominado políticas educacionales, tiene el potencial de demonstrar que la formación de los sistemas escolares nacionales emergió a partir de amplias relaciones internacionales. Palabras-clave: Historia de la educación. Políticas educacionales. Circulación de discursos. Intelectuales.

\section{Introdução}

Este texto é, antes de tudo, um exercício pelo qual se tentou perceber algumas relações entre duas áreas relevantes no âmbito da educação: história da educação e políticas educacionais. Nele pressupõe-se que a história da educação e as políticas educacionais têm um itinerário afim, se alerta para a conveniência de pensar as relações entre ambas na perspectiva da longa duração, assim como entender que se constituem entre saberes, conhecimentos, ação de intelectuais, circulação internacional ou transnacional de discursos, especificidades nacionais ou estrangeiras, transferências culturais.

Nesse sentido, entende-se que história da educação e políticas educacionais se informam mutuamente, em princípio sem hierarquias e de modo relacional. Atravessando estas duas expres- 
sões - história da educação e políticas educacionais - há uma ideia geral: a circulação internacional de discursos que, de um modo ou de outro, tem o potencial de estruturar, fixar, delimitar, circunscrever aquilo que pode ser considerado correto e verdadeiro. Aquilo que pode ser dito e aquilo que está interditado.

Para fazer este exercício de tentar perceber relações entre história da educação e políticas educacionais foram escolhidos quatro textos publicados na revista História da Educação, mantida pela Associação Sul-Rio-Grandense de Pesquisadores em História da Educação - Asphe:

1) Pedagogia como transferência cultural no espaço franco-suiço: mediadores e reinterpretações de conhecimento (1850-1900), de Alexandre Fontaine, publicado em 2014 no n. 42 da revista;

2) As exposições universais como mídia para a circulação transnacional de saberes sobre o ensino primário na segunda metade do século 19, de Klaus Dittrich, publicado em 2013 no n. 41;

3) A França, a escola republicana e o exterior: perspectivas para uma história internacional da educação no século 19, de Damiano Matasci, publicado em 2016 no n. 50;

4) Transferências e apropriações de saberes: Friedrich Bieri e a matemática para o ensino primário, de Circe Mary Silva da Silva, publicado em 2015 no n. 45.

O importante, no âmbito deste exercício, é perceber que ideias criadas, pensadas, fundamentadas pela pesquisa, pela ciência, propostas por intelectuais, lograram visibilidade e foram postas em circulação e, ao circularem, estruturaram modos de pensar, pautas, entendimentos, currículos, impressos, políticas. Enfim, ao circularem tornaram possíveis várias relações e contribuíram para estruturar um campo de ação denominado políticas educacionais.

\section{Primeiro texto: ideias que atravessaram as fronteiras}

O primeiro texto, de Alexandre Fontaine, se intitula Pedagogia como transferência cultural no espaço franco-suiço: mediadores e reinterpretações de conhecimento (1850-1900), e nele aborda-se a circulação dos conhecimentos pedagógicos no espaço franco-suíço.
Segundo Fontaine (2014, p. 189), “estudar as relações pedagógicas franco-romandas do século 19 torna-se instrutivo, no sentido em que esta abordagem permite analisar as modalidades de circulações de conhecimentos e de práticas escolares por uma relação assimétrica entre uma região e uma nação". Em termos gerais, o autor argumenta que as estruturas escolares nacionais são resultado de apropriações recíprocas e que nada mais internacional do que a formação dos sistemas escolares nacionais.

Fontaine (2014) estrutura o texto a partir de três aspectos: 1) busca interrogar-se acerca das motivações que podem levar um contexto cultural de recepção a desejar importar um conhecimento modelado em outro contexto; 2) questiona-se sobre o processo de mediação, sobre os atores individuais que, por diversas razões, permitem a transferência de um determinado saber; 3 ) estuda a transformação semântica que acompanha a transferência quando da passagem de um contexto cultural a outro.

Para perceber essas relações, em termos metodológicos, afirma ter-se utilizado do conceito de transferências culturais, definido nos seguintes termos:

Os estudos de transferência pretendem analisar as interações entre culturas e sociedades - ou frações e grupos pertencentes a uma sociedade - na sua dinâmica histórica, justificando as condições que marcaram o seu desencadeamento e o seu desenvolvimento, examinando os fenômenos de emissão, de divulgação, de recepção e de reinterpretação que os constituem, enfim esmiuçando os mecanismos simbólicos por meio dos quais se recompõem os grupos sociais e as estruturas que os sustentam. (WERNER, 2006 apud FONTAINE, 2014, p. 190).

Para demonstrar a circulação de conhecimentos e de práticas escolares, o processo de mediação, recepção, transformação semântica, apropriações recíprocas entre diferentes espaços, o autor apresenta alguns exemplos. Um deles é a manifestação de Ferdinand Buisson, que salientou, numa conferência proferida em 1916, que

[...] saber ler, escrever e contar não basta, todos estão de acordo, mas o que é necessário acrescentar? Inicialmente, sem dúvida, elementos de instrução cívica, pois o povo só é soberano se o cidadão for esclarecido. Há muito tempo, a Suíça agia com pre- 
caução, e essa foi a primeira importação que dela fizemos. (FONTAINE, 2014, p. 191).

Outro exemplo é que na França, pela lei de 27 de janeiro de 1880, as aulas de ginástica tornaram-se obrigatórias para os meninos, em especial para a prática de exercícios militares. Destaca que expatriados suíços desempenharam um papel relevante na promoção da ginástica na França e que Jules Ferry publicou, em 1881, um manual de ginástica e de exercícios militares para estudantes de escolas primárias. Esse manual foi feito a partir da inspiração do primeiro manual escolar publicado pela Confederação Suíça em 1876.

Há outras situações que o autor relaciona à circulação e transferência de saberes. Destaca-se a inclusão do Canto como tema obrigatório e as colônias de férias que, de um contexto original suíço ao contexto cultural francês, teriam gerado uma transformação semântica singular: "É importante notar a institucionalização destas como diretrizes políticas do governo: de fato, assim que Ferdinand Buisson, convencido por Cottinet sobre o bem fundado das colônias para a juventude francesa, decidiu institucionalizar a experiência" (FONTAINE, 2014, p. 202).

Uma das principais conclusões de Fontaine (2014, p. 204) é que

[...] por meio deste estudo de caso referente às transferências pedagógicas franco-romandas, procurou-se demonstrar que a organização dos sistemas escolares europeus resulta de apropriações recíprocas, mais ou menos dissimuladas, e se constitui num resultado de um fenômeno eminentemente internacional. Estudar certas referências suíças da escola republicana francesa revela uma série de mediações apagadas, bem como uma quantidade de empreendimentos coletivos que se tornaram possíveis em virtude da criação de redes que favoreceram a importação massiva de métodos e de práticas pedagógicas elaboradas de maneira internacional.

Dito isso, prossegue com um indício de que o Brasil não escapou desse empreendimento:

Assim, a ciência da educação alimentou-se de transferências culturais. $\mathrm{O}$ mesmo aconteceu com o continente sul-americano. Basta pensarmos nos trabalhos de Maria Helena Camara Bastos (2000), que demonstrou, de maneira pertinente, a recepção do pensamento de Buisson no Brasil pelos itinerários de Rui Barbosa (1849-1923) e de Joaquim José de Menezes Vieira (1848-1897). (FONTAINE, 2014, p. 204).

Nas considerações finais do texto, Fontaine $(2014$, p. 205) ressalta que se for levada em conta a elaboração da Ratio studiorum, no fim da Idade Média, há práticas e métodos que atravessam as fronteiras por meio de mediadores e se declinam em função de contextos locais específicos e, portanto, "um dos numerosos desafios da pesquisa em história da educação consiste em desconstruir os modelos escolares nacionais contemporâneos, a fim de reformular as filiações seguidamente ocultadas e as múltiplas referências estrangeiras que as alimentam".

Diante da pauta desse texto, pode-se relacionar inúmeras expressões que merecem atenção no âmbito da relação entre a história da educação e as políticas educacionais, dentre as quais pode-se citar: circulação de conhecimentos, apropriações, contexto cultural de recepção, processos de mediação, transformações semânticas, transferências culturais, seleção-transmissão-reinterpretação. Pelos exemplos apresentados, Fontaine (2014) procura demonstrar que as ideias que atravessaram as fronteiras foram importantes para a instituição de políticas educacionais, que assumiram um caráter eminentemente internacional.

\section{Segundo texto: aprender com o estrangeiro nas exposições universais}

O segundo texto, de Klaus Dittrich, intitula-se As exposições universais como mídia para a circulação transnacional de saberes sobre o ensino primário na segunda metade do século 19. Nele aborda-se o tema da circulação de saberes sobre educação e, em especial, sobre os progressos no ensino primário possibilitados pelo movimento de alguns atores. Concentra-se em examinar quatro países: Japão, França, Estados Unidos e Alemanha e argumenta que a transferência cultural acerca do ensino primário foi operada por meio das seções que, nas exposições universais, mostraram os progressos quanto aos objetos pedagógicos, aos documentos redigidos, às maquetes, às plantas de prédios escolares, bem como aos modelos adotados pelas trocas e aos aprendizados das experiências 
do estrangeiro. Em termos bem gerais, Dittrich (2013) entende que não convém esquecer que as exposições universais do século 19 foram um dos meios de comunicação para os atores profissionais e científicos.

Ele argumenta que

[...] a partir de 1862 as exposições universais continham seções escolares, as quais possuíam certo número de elementos que se repetiram em todas as exposições sucessivas. Primeiro apresentava-se o aspecto físico das instituições educativas, seus planos, depois as fotografias e as escolas-modelo reconstruídas para a exposição. Em seguida objetos pedagógicos eram apresentados em grande número, de canetas a máquinas de calcular e quadros murais. Além do mais, as exposições se pareciam com bibliotecas, porque continham livros pedagógicos e manuais escolares. Finalmente, trabalhos de alunos tinham a função de provar o sucesso dos métodos aplicados. Além das exposições escolares propriamente ditas, conferências e congressos nacionais foram organizados no contexto das exposições universais a partir de 1876. (DITTRICH, 2013, p. 215).

Informa, ainda, que as exposições eram frequentadas por funcionários dos governos, professores e especialistas da educação e que isto se devia ao fato de que, para estas pessoas, as exposições eram um meio de comunicação com seus pares, para além das fronteiras nacionais.

As exposições também eram frequentadas com intenções bem específicas, dentre as quais Dittrich (2013) assinala as seguintes: a) eram ocasiões para aprender com o estrangeiro, informar-se e aprender algo em benefício de seu contexto institucional; b) demonstrar o sucesso de uns sobre outros no contexto de competição entre sociedades hoje classificadas como imperialistas; c) iniciar colaboração internacional entre especialistas de diferentes países.

Nessa situação Dittrich (2013) analisa as exposições universais pela abordagem das transferências culturais, no âmbito das quais se distinguem diferentes fases: 1) uma parte dos atores constata déficits e procura soluções potenciais no exterior; 2) segue-se uma fase de contato e de mediação; 3) o saber estrangeiro é adaptado e institucionalizado, ou então, recusado. Neste contexto "as exposições se prestaram, especialmente, para a fase de contato e mediação. Por ocasião da visitação das missões às exposições, os especialistas escreviam importantes relatórios, testemunhos materiais desta mediação e que constituem a fonte principal do estudo" (DITTRICH, 2013, p. 216).

No artigo, Dittrich (2013) afirma que se concentrou nas experiências de atores de quatro países que frequentaram as exposições com a finalidade de informarem-se sobre o ensino primário. Para cada país procurou identificar conjunturas, interrogar-se sobre os atores e os déficits que eles perceberam, analisar suas participações nas exposições e os resultados deste engajamento. Tudo isso a fim de "relacionar as conjunturas, comparar a apropriação dos saberes em diferentes contextos nacionais, o que pode conduzir, talvez, a uma verdadeira história transnacional, que combina as abordagens das transferências culturais e da comparação" (DITTRICH, 2013, p. 216).

Klaus Dittrich (2013) relata o caso do Japão, onde a inspiração francesa e estadunidense foi central. Informa que na fase inicial da institucionalização do sistema escolar japonês a frequência às exposições universais foi um meio de comunicação para entrar-se em contato com os progressos havidos no exterior. Informa que houve missões japonesas nas exposições realizadas em Londres, 1862, e em Paris, 1867. Em Viena, 1873, a missão foi integrada por, aproximadamente, cinquenta pessoas, na maior parte funcionários públicos de alto escalão. Já para a exposição da Filadélfia, em 1876, a missão foi dirigida pelo vice-ministro da Educação e Klaus Dittrich (2013) salienta que os japoneses estudaram, sobretudo, as representações de outros países, viajaram para diferentes regiões dos Estados Unidos e do Canadá e participaram de congressos pedagógicos. Na Exposição Universal de 1878, em Paris, os japoneses entraram em contato com os pedagogos franceses e, após o encerramento da exposição, receberam uma boa parte dos materiais dos outros países.

Para Klaus Dittrich (2013, p. 219), ficou claro que "os funcionários do alto escalão do Ministério da Educação japonês utilizaram as exposições dos anos 1870 com o objetivo de apropriarem-se dos saberes para a institucionalização de seu sistema de ensino". 
No contexto francês a referência ao estrangeiro já havia aparecido como possível solução aos defeitos franceses. Dittrich (2013) destaca os relatórios de Célestin Hippeau, que visitou muitos países e redigiu monografias sobre seus sistemas de educação, e a missão dirigida, em 1876, por Buisson à Exposição Universal da Filadélfia:

Os especialistas franceses não ficaram somente na exposição: viajaram para diversos Estados e ao Canadá, visitaram instituições escolares e participaram de congressos. Disso resultaram contatos intensos com os grandes nomes da educação americana da época, incluindo, por exemplo, John D. Philbrick. (DITTRICH, 2013, p. 220).

Nos Estados Unidos, Dittrich (2013, p. 222) afirma que havia uma intenção "de tornar o ensino mais prático, de não oferecer somente uma cultura geral, mas também conhecimentos que os jovens pudessem aplicar no mundo do trabalho". Assim, se na década de 1870 o ensino técnico era percebido como algo especificamente europeu, outra perspectiva emergiu quando John D. Runkle, presidente do Massachusetts Institute of Technology, ao visitar as instalações da exposição na Filadélfia, encontrou a representação das escolas politécnicas russas de Moscou e de São Petersburgo. Dali em diante "a educação americana [...] não foi mais a mesma" (DITTRICH, 2013, p. 222).

John D. Runkle preocupava-se em como organizar a formação prática dos futuros engenheiros e percebeu que

[...] os pedagogos russos haviam inventado um novo método de como ensinar aos estudantes procedimentos passo a passo em laboratórios especialmente criados para fins pedagógicos. Os gestores russos apresentavam as escolas politécnicas bem equipadas e metodologicamente inovadoras com certo orgulho nas exposições dos anos 1870. Runkle (1876) descobriu este método na Filadélfia e ficou impressionado porque tal método oferecia uma solução para suas próprias preocupações. Seguiu-se, então, um vasto trabalho de apropriação do método russo, como foi denominado doravante na América. Ele estabeleceu contatos intensos com os responsáveis russos e mesmo tornou-se um membro honorário do Conselho de Administração da Escola Politécnica de Moscou. (DITTRICH, 2013, p. 222).

Dittrich (2013, p. 222) assinala, ainda, outros visitantes de exposições universais que buscaram inspiração para seus planos: Calvin M. Woodward, Charles B. Stetson, Walter Smith, Philbrick, Wickersham, por exemplo, bem como destaca que "um número bem maior de pedagogos americanos utilizaram as exposições universais para informar-se sobre o ensino técnico europeu, daí que se deve estabelecer um discurso muito mais vasto", ou seja, Dittrich (2013, p. 225) demonstra que "no contexto das exposições universais dos anos 1870, observa-se um intenso trabalho de apropriação por parte dos pedagogos americanos interessados no ensino técnico europeu".

O quarto caso analisado por Dittrich (2013) foi o da Alemanha, que teve uma participação menos frequente nas exposições universais, o que acarretou um menor número de relatórios redigidos após estes eventos, se comparados àqueles publicados na França e nos Estados Unidos.

Dittrich (2013) destaca que os alemães se interessavam por questões específicas, como os bancos escolares, abordada por Hermann Cohn. Ele frequentou as exposições de 1867, 1873 e 1878, estudou os bancos de escola e outros aspectos de higiene escolar. Contudo, destaca que o caso mais sistemático de apropriação de saberes estrangeiros por meio das exposições foi Alwin Pabst, que participou da Exposição Universal de Paris, em 1900, e de Saint-Louis, em 1904. Segundo ele, "a Alemanha devia aproveitar as experiências americanas. Do outro lado do Atlântico Pabst teve um vasto programa de visitas a escolas, bem como encontrou todos os grandes pedagogos americanos ligados à nova educação" (DITTRICH, 2013, p. 226). Em resumo, alguns especialistas alemães tentaram tornar o ensino alemão mais prático, referindo-se às experiências americanas e francesas.

Em síntese, Klaus Dittrich (2013, p. 228) se esforça para demonstrar que as exposições universais

[...] desempenharam um papel fundamental para a circulação transnacional de saberes pedagógicos durante a segunda metade do século 19. Foram palcos para o contato com os pares estrangeiros, para a coleta de informações e para a aquisição de objetos e literatura. As exposições, como meio de comunicação, combinaram-se com as visitas das missões, com a redação e a circulação dos relatórios, com os museus pedagógicos e os congressos internacionais. 
Os atores iam às exposições por razões bem específicas e, como se viu, uma de suas preocupações era o desenvolvimento do ensino em seus próprios contextos. Seu enraizamento nos debates nacionais diferiu, consideravelmente, de país a país.

Do mesmo modo, e com proximidade com Alexandre Fontaine (2014), a pauta deste texto permite outra coleção de expressões a partir das quais se pode pensar inúmeras relações entre a história da educação e as políticas educacionais: além das fronteiras nacionais, apropriação dos saberes, atores com contatos intensos, circulação transnacional de saberes pedagógicos, colaboração internacional, comunicação, congressos internacionais, enraizamento nos debates nacionais, exposições universais, transferências culturais e comparação, trocas e aprendizados das experiências do estrangeiro, história transnacional. Em síntese, ao viajar para conhecer e aprender com o estrangeiro, inúmeros profissionais promoveram a circulação internacional de saberes, mobilizaram relações de colaboração e promoveram mudanças nos respectivos contextos nacionais.

\section{Terceiro texto: intercâmbio e cooperação mundial}

O terceiro texto se intitula $A$ França, a escola republicana e o exterior: perspectivas para uma história internacional da educação no século 19 , de Damiano Matasci, e foi publicado no n. 50 da revista História da Educação.

Matasci (2016, p. 139) se propõe a tratar

[...] dos modos pelos quais a circulação internacional das ideias pedagógicas estruturou a elaboração do sistema escolar francês no fim do século 19. Embora seguidamente associada ao processo de nacionalização da sociedade, a escola da Terceira República se construiu, de fato, seguindo modelos e exemplos estrangeiros.

Matasci (2016, p. 141) argumenta que é possível perceber essa situação de modo especial a partir "do século 19, no momento em que as nações ocidentais se engajam simultaneamente na elaboração dos sistemas escolares modernos, criam e alimentam um vasto sistema de intercâmbios e de observações mútuas".
Ao tomar o exemplo francês, Matasci (2016, p. 141) propõe o que denomina "perspectivas de pesquisa para uma história internacional da educação", pela qual busca demonstrar

[..] como o contato internacional e o recurso à comparação - tão presentes nos debates públicos de hoje - constituem uma dimensão particularmente importante no processo de construção do sistema escolar moderno no século 19. O problema é de saber em que medida as experiências referentes à instrução pública efetuadas em outros países ocidentais orientaram os debates na Terceira República. Para responder a essa questão focaliza-se as reformas do ensino primário e secundário que constituem um observatório privilegiado para captar esses fenômenos. Isso por duas razões: por um lado porque esses debates, principalmente aqueles relativos à instrução obrigatória ou à modernização do ensino secundário, se inscrevem num contexto internacional e mobilizam, de uma maneira permanente, as referências estrangeiras. Por outro porque, comparando essas duas áreas, é possível esclarecer a diversidade dos costumes estrangeiros e as diferentes relações que os meios reformadores franceses conservam em relação às experiências internacionais.

A partir da relação da história da educação entre o local, o nacional e o internacional, Matasci (2016, p. 142) busca "examinar a relação que a escola francesa - e, de uma maneira mais ampla, o processo de nacionalização do sistema escolar mantém com o exterior". Para isso ele afirma que "convém deslocar os debates franceses para os circuitos europeus das ideias pedagógicas do século 19 e avaliar o papel que a dimensão internacional pode desempenhar na elaboração de um modelo francês de instrução pública" (MATASCI, 2016, p. 142). Ele reforça que

[...] esses fenômenos impõem a reconfiguração do processo de socialização das novas gerações e a criação de estruturas que respondam a novas exigências educativas. Para isso os reformadores escrutam as realizações de seus vizinhos e observam com atenção as experiências em curso. O processo reformador que leva à instauração de um sistema escolar público, na maior parte dos países ocidentais, se caracteriza por intercâmbios, circulações e contatos não fortuitos entre as nações [...]. Reproduzindo uma famosa fórmula de Anne-Marie Thiesse (2001), não haveria desde então nada mais internacional do que a defi- 
nição das políticas escolares nacionais. (MATASCI, 2016, p. 143).

No que designa como a "globalização da reforma escolar europeia" (MATASCI, 2016, p. 143), aponta três dimensões que precisam atenção: em primeiro lugar convém examinar o conjunto das atividades que ao longo do século 19 visaram produzir e acumular um saber sobre o exterior. Um dos exemplos mais representativos foram as missões pedagógicas. A partir da metade do século 19, o ministério francês da instrução pública encarregou um número expressivo de pessoas, em especial professores universitários e inspetores escolares, de viajarem para diversos países a fim de estudar os procedimentos pedagógicos, os diferentes problemas relacionados com a instrução pública e as soluções ali encontradas. Cabia-lhes fazer uma reflexão sobre as possíveis importações aplicáveis ao sistema escolar nacional. Esta prática, que começou no início do século 19, tal como a viagem de Victor Cousin (1832) à Prússia em 1831, intensificou-se a partir dos anos 1870 e só foi interrompida pela Primeira Guerra Mundial.

Matasci (2016) afirma que foram mais ou menos 130 missões entre 1842 e 1914 e que a Alemanha foi o país mais procurado, seguido pelos Estados Unidos, a Suíça, a Inglaterra, os países escandinavos e a Itália. Os relatórios da participação nessas missões ilustram a necessidade de aprender com o exterior e, neste sentido,

[...] na segunda metade do século 19 se desenvolveram, assim, uma série de práticas que alimentam um verdadeiro regime circulatório (SAUNIER, 2008) que permitiu aos reformadores franceses integrar nos seus discursos um vasto horizonte de referências internacionais. Essas atividades mobilizam o estrangeiro em função das necessidades internas ditadas pelas reformas escolares da época num contexto - não devemos esquecer - de nacionalização do sistema educativo. (MATASCI, 2016, p. 144).

Em segundo lugar, Matasci (2016) indica que, se por um lado essas dinâmicas de circulação serviram como possibilidade para produção e de constituição de um saber, por outro serviram para a promoção do intercâmbio e da cooperação mundial: "os reformadores franceses são efetivamente muito ativos no seio do movimento de reforma da instrução pública, criada na Europa na segunda metade do século 19, e que se dota progressivamente de estruturas próprias permanentes" (MATASCI, 2016, p. 144).

Nesse contexto, Matasci (2016, p. 145) também destaca que a ação dos franceses pode ser estudada sob o prisma das seções escolares das exposições universais e que

[...] esses eventos testemunham uma dupla dinâmica. Por um lado o aprendizado, pois os reformadores de todos os países tinham a oportunidade de tomar conhecimento da evolução escolar internacional. Por outro a auto-representação. De fato, a França participou, de uma maneira muito especial, das exposições com o objetivo explícito de contribuir com certa diplomacia cultural, passando pela evidência das pretendidas conquistas escolares da Terceira República e respondendo à vontade de mostrar mundialmente $\mathrm{a}$ imagem de um país que investe na educação. Além de certa retórica essa citação salienta a importância dos intercâmbios internacionais e a necessidade, exposta muito claramente, de se comparar e de se inspirar nas experiências estrangeiras para atenuar os defeitos de um sistema escolar ou para discutir problemas comuns aos países ocidentais.

Matasci (2016) apresenta outro dado importante ao informar que todas essas atividades - congressos, exposições, missões pedagógicas - permanecem relativamente informais e pouco codificadas ao longo do século 19. Entretanto, a partir do início do século 20 essa dinâmica de intercâmbios e de contatos internacionais mudou quando foram criados os primeiros departamentos e federações internacionais na área da educação. Ele cita a criação de instituições como o Comitê Permanente dos Congressos Internacionais do Ensino Técnico, fundado em Bordeaux, em 1895, e composto por especialistas de renome, ou o Bureau Internacional do Ensino Secundário (1912), ambas federações que reuniam associações nacionais de professores de diversos países europeus. Neste caso, Matasci (2016) destaca que essas redes procuraram promover as perspectivas corporativistas dessas categorias profissionais, mais do que propor uma reflexão científica sobre os problemas educativos.

Matasci (2016) afirma ainda que o exame das reformas francesas do ensino primário e secundário permite esclarecer as diferentes formas de recepção e de reapropriação dos modelos estrangeiros. Para 
ele, "a esse respeito é particularmente interessante indagar as dinâmicas dessa recepção, que é seletiva e parcial" (MATASCI, 2016, p 146).

Para concluir, Matasci (2016) destaca dois pontos: 1) a passagem pelo internacional se explica menos pela vontade de promover a cooperação com outros países do que pela necessidade de resolver problemas internos. Segundo ele, essa é a lógica da internacionalização: responder a desafios nacionais e trabalhar para transformar o contexto nacional; 2) a natureza e a evolução do processo de internacionalização: se durante muito tempo foi informal e relativamente pouco estruturada, a partir do início do século 20 ela prefigurou outras mudanças que aconteceram após a Primeira e a Segunda Guerra Mundial, com a criação e o desenvolvimento das instituições internacionais, ou seja, a ação desempenhada pelas organizações como o Bureau Internacional de Educação (1925), a Unesco (1945), o Banco Mundial e a OCDE marca uma profunda inflexão na maneira de pensar a educação em um mundo cada vez mais globalizado.

Nesse texto também há um mix de termos a partir dos quais se pode pensar inúmeras relações entre a história da educação e as políticas educacionais: circulação internacional das ideias pedagógicas, modelos e exemplos estrangeiros, sistema de intercâmbios e de observações mútuas, história internacional da educação, circuitos de ideias pedagógicas, nada mais internacional do que a definição das políticas escolares nacionais, missões pedagógicas, regime circulatório, vasto horizonte de referências internacionais, promoção do intercâmbio e de cooperação mundial, redes permanentes de intelectuais, virada organizadora do internacionalismo, conexões internacionais criadas pelos reformadores. Contudo, uma ideia se destaca: o processo de internacionalização formalizou-se por meio de instituições no âmbito das quais as políticas educacionais passaram a ser pensadas a partir das perspectivas do intercâmbio e da cooperação mundial.

\section{Quarto texto: transferências e apropriações de saberes}

O quarto texto intitula-se Transferências $e$ apropriações de saberes: Friedrich Bieri e a ma- temática para o ensino primário, é assinado por Circe Mary Silva da Silva e foi publicado no n. 45 da revista História da Educação.

Nesse texto, destaca-se que, pela análise da obra de Friedrich Bieri (1844-1924), foi possível identificar apropriações de saberes produzidos em países de língua alemã no ensino brasileiro. Circe da Silva (2015) apresenta um perfil de Friedrich Bieri, relata o processo de transferência de conhecimentos ocorrido e sua atuação na Província do Rio Grande do Sul, bem como informa que pela análise da obra de Bieri foi possível concluir que este foi um dos pioneiros na produção de livros didáticos para escolas teuto-brasileiras, assim como adotou uma proposta pedagógica germânica adaptada ao contexto local e influenciada pelo método de August Grube e da reformulação deste por Jakob Egger.

Circe da Silva (2015) apresenta Friedrich Bieri como um imigrante suíço que chegou ao Brasil em 1871 e como um dos primeiros a escrever livros didáticos para o ensino primário de Matemática, em língua alemã, visando ao público das escolas teuto-brasileiras. Ele iniciou essas publicações em 1873, com o Livro de cálculo para as escolas alemãs no Brasil. Sobretudo a autora o apresenta como uma pessoa que rompeu

[...] uma barreira territorial, um agente europeu [que] transpôs conhecimentos matemáticos produzidos num lugar, com maior tradição em ensino e formação de professores, para um novo lugar - Sul do Brasil, no século 19 - com um contingente significativo de imigrantes germânicos ainda pouco letrados. (SILVA, 2015, p. 45).

Destaca-se, ainda, a publicação para o ensino bilíngue de alemão e português do Livro para aprender e ler em alemão, de 1876. A carência de livros escolares teria motivado Bieri a se dedicar a escrevê-los para as escolas teuto-brasileiras.

Circe da Silva (2015) aponta que Bieri chegou à cidade de São Leopoldo em 1871, foi designado professor da escola paroquial evangélica e nela permaneceu até 1877 . No início da década de 1880 seu nome aparece como professor da sétima cadeira, Língua Alemã, e como professor substituto de Desenho. Em 1886 ainda atuava na Escola Normal e foi novamente nomeado professor substituto de Desenho. Seu nome aparece, constantemente, nas 
relações de professores da Escola Normal que atuavam como examinadores nos exames anuais.

De acordo com Circe da Silva (2015, p. 50), os saberes que Bieri, formado na escola suíça e conhecedor das ideias de Pestalozzi, trouxe para o Brasil foram modificados, "pois ao desempenhar uma função de intermediário fez, ele próprio, sua leitura e interpretação. Considerando o contexto local ele realizou um elo entre a produção e a recepção". Afirma ainda que à "medida em que Bieri se inseriu no contexto educacional e começou a redigir livros didáticos para as escolas teuto-brasileiras, tornou-se agente que usou o ensino para transmitir novas ideias, principalmente aquelas relacionadas a metodologia da Aritmética" (SILVA, 2015, p. 50).

Circe da Silva (2015) relaciona as experiências e formação para o magistério obtidas na Suíça como relevantes para a atuação de Friedrich Bieri que, com isso, assumiu atividades relacionadas com ensino em diferentes escolas, avaliador de exames e autor de livros didáticos. A autora diz ainda que Bieri adaptou para o contexto local os métodos de Grube e de Egger e conclui que

Bieri, como um agente de mediação, transferiu um método de ensino da Matemática criado para o contexto cultural europeu, onde já existia uma estrutura educacional organizada, com cursos para formação de professores, estágios para a prática docente e produção de livros didáticos, para um novo contexto cultural - o Brasil. (SILVA, 2015, p. 63).

Ao escrever e publicar livros para o ensino da Matemática e trazer uma metodologia europeia, promoveu inovação ao adaptá-los ao contexto nacional. ${ }^{1}$

Assim como nos demais textos, a pauta de Circe Silva (2015) indica a possibilidade de pensar relações entre a história da educação e as políticas educacionais a partir, por exemplo, das dinâmicas de apropriações de saberes, transferência de conhecimentos, rompimento de barreiras territoriais, produção e a recepção de bens culturais e a ação de agentes de mediação. Por meio deste texto é possível perceber um dos modos pelos quais a circulação de ideias relacionou Europa e Brasil, assim como

1 Situação similar pode ser vista, dentre outros, em Ensino de aritmética no Rio Grande do Sul: a contribuição de Luiz Schuler, 1904 (QUADROS; BISOGNIN, 2015). instituiu práticas num contexto específico: o Rio Grande do Sul do final do século 19.

\section{Considerações finais}

Enfim, eis a preocupação principal deste exercício: pela história da educação pode-se perceber como diferentes discursos circularam e instituíram, ao longo do tempo, conceitos e práticas no âmbito das políticas educacionais.

Ou seja, esta parece ser a fronteira do momento no âmbito da história da educação: perceber, informar, demonstrar os modos pelos quais as redes de relações entre países, regiões e pessoas compareceram na formulação das respectivas políticas nacionais. Talvez esta possa ser uma das importâncias ou contribuições da história da educação para a sociedade: mostrar como aquilo que estamos acostumados a dizer é resultado de uma ampla rede de relações cuja autoria não é necessariamente nacional, bem como por as coisas nos seus devidos lugares: o que conseguimos pensar acerca das políticas educacionais é circunscrito pelos discursos que circulam internacionalmente.

Além disso, há outras conclusões que, embora óbvias, podem ser repetidas:

1. A expressão ao longo do tempo é relevante: com ela indica-se que convém perceber as relações entre história da educação e políticas educacionais na perspectiva da longa duração, proposta no âmbito da Escola dos Annales;

2. Convém pensar as políticas educacionais entre saberes, conhecimentos, ação de intelectuais, circulação internacional ou transnacional de discursos ou entre especificidades nacionais ou estrangeiras;

3. Pode ser produtivo estudar as relações entre transferências culturais e seleção-transmissão-reinterpretação ou como os discursos ultrapassam as fronteiras, envolvem numerosos mediadores e circunscrevem aquilo que pode ser considerado correto e verdadeiro no âmbito das políticas ou as formas pelas quais as apropriações funcionam num contexto cultural de recepção. Não há como abordar políticas educacionais, por exem- 
plo, sem atenção ao que é dito no âmbito da ONU, Unesco e OECD: como ideias são postas em circulação e estruturam o que pode ser pensado e dito acerca das políticas educacionais. Neste caso as perspectivas da educação comparada podem ser relevantes;

4. Todavia, as políticas educacionais, sempre alvo de disputas ideológicas ou político-partidárias, e embora a sua proeminência e vontade colonizadora das mentes e corações no tempo presente, não são hegemônicas: há outras perspectivas que podem ser percebidas em inúmeros lugares, tais como, por exemplo: no site da Perestroika, com o seu curso denominado Nova; no site da Descola; no site da Educação fora da caixa; no site da Hackademia; no site da Fundação Lemann. Ou seja, outras pautas, outras perspectivas, outros modos de fazer, outras formas de estruturar o pensamento fora das políticas educacionais oficiais, produzidos fora das universidades e dos seus intelectuais. Talvez esta possa ser uma pauta interessante: perceber como se estruturam estas formas, o que propõem, que discursos fazem circular.

Entretanto, além dessa possibilidade talvez haja outra mais importante e que se encontra expressa por Maria Stephanou (2016, p. 6) na apresentação do n. 50 da revista História da Educação:

Se os acontecimentos são, como nos ensina Certeau (1994), o que eles se tornam, seremos capazes de examinar tradições e mudanças nas abordagens da história da educação [e das políticas educacionais], suas narrativas, perfilações teóricas, eleição de objetos, atravessados pelos acontecimentos do tempo presente, de modo a pensarmos em como se constituem tão somente em seu depois?

Em síntese, as relações entre a história da educação e as políticas educacionais são campos abertos para estudo, em especial na perspectiva reiterada ao longo deste texto: que ambas têm um itinerário relacionado, o qual convém ser pensado na longa duração e que se constitui pela relação entre saberes, conhecimentos, ação de intelectuais e ampla circulação internacional de discursos.

\section{REFERÊNCIAS}

DITTRICH, Klaus. As exposições universais como mídia para a circulação transnacional de saberes sobre o ensino primário na segunda metade do século. História da Educação, Porto Alegre, v. 18, n. 41, p. 213-234, 2013.

FONTAINE, Alexandre. Pedagogia como transferência cultural no espaço franco-suíço: mediadores e reinterpretações de conhecimento (1850-1900). História da Educação, Porto Alegre, v. 18, n. 42, p. 187-207, 2014.

MATASCI, Damiano. A França, a escola republicana e o exterior: perspectivas para uma história internacional da educação no século 19. História da Educação, Porto Alegre, v. 18, n. 50, p. 139-155, 2016.

QUADROS, Claudemir de; BISOGNIN, Vanilde. Ensino de aritmética no Rio Grande do Sul: a contribuição de Luiz Schuler, 1904. Acta Scientiae, Canoas, RS, v. 17, p. 24-40, 2015. Disponível em: <http://www.periodicos. ulbra.br/index.php/acta/article/view/1454/1144>. Acesso em: 22 ago. 2016.

SILVA, Circe Mary Silva da. Transferências e apropriações de saberes: Friedrich Bieri e a matemática para o ensino primário. História da Educação, Porto Alegre, v. 19, n. 45, p. 43-66, 2015.

STEPHANOU, Maria. Apresentação: um espaço para palavras, memórias e saberes: contributos de uma revista ao longe. História da Educação, Porto Alegre, v. 20, n. 50, p. 5-10, 2016.

WERNER, Michael. Transferts culturels: le dictionnaire des sciences humaines. Paris: PUF, 2006.

Recebido em: 07/05/2017

Aprovado em: 26/06/2017 